\title{
Substitution of Heavy Complementarity Determining Region 3 (CDR-H3) Residues Can Synergistically Enhance Functional Activity of Antibody and Its Binding Affinity to HER2 Antigen
}

\author{
Seung Kee Moon ${ }^{1,2,4}$, So Ra Park ${ }^{1,4}$, Ami Park', Hyun Mi Oh', Hyun Jung Shin', Eun Ju Jeon', Seiwhan Kim, \\ Hyun June Park', Young Joo Yeon , and Young Je Yoo ${ }^{2, *}$
}

To generate a biobetter that has improved therapeutic activity, we constructed scFv libraries via random mutagenesis of several residues of $C D R-H 3$ and $-L 3$ of hu4D5. The scFv clones were isolated from the phage display libraries by stringent panning, and their antiproliferative activity against HER2-positive cancer cells was evaluated as a primary selection criterion. Consequently, we selected AHO6 as a biobetter antibody that had a 7.2-fold increase in anti-proliferative activity $\left(I C_{50}\right.$ : $0.81 \mathrm{nM}$ ) against the gastric cancer cell line NCl-N87 and a 7.4-fold increase in binding affinity $\left(K_{D}: 60 \mathrm{pM}\right)$ to HER2 compared to hu4D5. The binding energy calculation and molecular modeling suggest that the substitution of residues of CDR-H3 to W98, F100c, A101 and L102 could stabilize binding of the antibody to HER2 and there could be direct hydrophobic interactions between the aromatic ring of W98 and the aliphatic group of I613 within HER2 domain IV as well as the heavy and light chain hydrophobic interactions by residues $\mathrm{F100C}$, A101 and L102 of CDR-H3. Therefore, we speculate that two such interactions were exerted by the residues W98 and F100c. A101 and L102 may have a synergistic effect on the increase in the binding affinity to HER2. AHO6 specifically binds to domain IV of HER2, and it decreased the phosphorylation level of HER2 and AKT. Above all, it highly increased the overall level of p27 compared to hu4D5 in the gastric cancer cell line $\mathrm{NCl}$ N82, suggesting that AHO6 could potentially be a more efficient therapeutic agent than hu4D5.

\footnotetext{
${ }^{1}$ Bio Medicine Lab., CKD Research Institute, ChongKunDang Pharm., Yongin 446-916, Korea, ${ }^{2}$ Graduate Program of Bioengineering, ${ }^{3}$ The
Institute of Molecular Biology and Genetics, Seoul National University, Yongin 446-916, Korea, ${ }^{2}$ Graduate Program of Bioengineering, ${ }^{3}$ The
Institute of Molecular Biology and Genetics, Seoul National University, Seoul 151-742, Korea, ${ }^{4}$ These authors contributed equally to this work. Seoul 151-742, Korea, ${ }^{4}$ These auth
${ }^{*}$ Correspondence: yjyoo@snu.ac.kr
}

Received 3 September, 2015; revised 13 October, 2015; accepted 26 October, 2015; published online 7 January, 2016

Keywords: antibody optimization, anti-proliferative activity, binding affinity, HER2, phage display, random mutagenesis

elSSN: 0219-1032

(c) The Korean Society for Molecular and Cellular Biology. All rights reserved.

(9) This is an open-access article distributed under the terms of the Creative Commons Attribution-NonCommercial-ShareAlike 3.0 Unported License. To view a copy of this license, visit http://creativecommons.org/licenses/by-nc-sa/3.0/. significant improvements in cancer treatment. Disease-free survivals at 3 years were $75.4 \%$ and $87.1 \%$ with chemotherapy alone and in combination with Herceptin, respectively, in patients with HER2-overexpressing metastatic breast cancer efit, most patients who have an initial response to Herceptin develop resistance within one year of treatment initiation.

Accordingly, the community needs to develop another antiHER2 antibody with improved efficacy. A popular strategy to improve the binding affinity and efficacy of the antibody is

\section{INTRODUCTION}

HER2 is a member of the ErbB/HER (Human epidermal growth factor receptor) family, which consists of EGFR, HER2, HER3 and HER4, and plays important roles in growth, differentiation and survival in cancer cells as well as in normal cells (Nicolas et al., 2008). In contrast to other HER family members, HER2 does not require ligands for receptor-receptor interactions (Nicolas et al., 2008). In cancer cells, the HER2 protein can be expressed up to 100 times more than in normal cells (2 million versus 20,000 per cell) (Shepard et al., 1991). Such overexpression or amplification of HER2 promotes the formation of receptor homo- and heterodimers with other HER family members, leading to uncontrolled cell proliferation and tumor growth (Mayumi and Michihiko, 2006). Therefore, HER2 has been investigated as a promising therapeutic target for cancer. Particularly, targeted therapy using anti-HER2 monoclonal antibodies such as Herceptin (Trastuzumab, hu4D5, binds to domain IV), Kadcyla (Trastuzumab-maytansinoid, antibody-drug conjugate) and Perjeta (Pertuzumab, binds to domain II) has been used to treat HER2 positive cancers.

Herceptin (trastuzumab, CAS Registry No. 180288-69-1) launched by Genentech in October 1998, is the humanized monoclonal antibody hu4D5. It binds to extracellular domain (ECD) IV of the HER2 receptor, subsequently inhibits its downstream PI3K-Akt signaling (Hudziak et al., 1989; Sliwkowski et al., 1999; Yakes et al., 2002) and induces cell cycle arrest via the induction of cyclin-dependent kinase inhibitor p27/kip1 and apoptosis (Carter et al., 1992) in metastatic HER2-positive breast and gastric cancer cells, which in turn inhibits HER2mediated tumor growth.

A combination of Herceptin with chemotherapy has shown (Romond et al, 2005). However, despite its proven clinical ben- 
mutagenesis, and particularly, substitution of the residues at some positions of CDR-H and CDR-L would be considered. Based on this strategy, it was previously reported that the substitution of residues in the CDRs of hu4D5 influences antibody affinity (Gerstner et al., 2002).

In the previous study, Gerstner et al. constructed phagedisplayed Fab libraries targeting 19 positions of hu4D5, including $\mathrm{R} 50\left(\mathrm{~V}_{\mathrm{H}}\right), \mathrm{W} 95\left(\mathrm{~V}_{\mathrm{H}}\right), \mathrm{Y} 100 \mathrm{a}\left(\mathrm{V}_{\mathrm{H}}\right)$ and $\mathrm{H} 91\left(\mathrm{~V}_{\mathrm{L}}\right)$, known to be important in binding to the HER2 molecule (Gerstner et al., 2002; Kelly and O'Connell, 1993). The libraries consisted of five groups with randomized 5-7 residues. Through screening, the binding affinity of a single mutant $\mathrm{D} 98\left(\mathrm{~V}_{\mathrm{H}}\right) \mathrm{W}\left(\mathrm{K}_{\mathrm{D}} 0.11 \mathrm{nM}\right)$ was increased 3-fold compared to the parent antibody hu4D5, but its anti-cancer activity was not reported. The authors also suggested that further improvement in binding affinity might be found using alternative methods of binding selection or targeting more variable positions (Gerstner et al., 2002). However, there have been no reports of success in screening variants superior to $\mathrm{D} 98\left(\mathrm{~V}_{\mathrm{H}}\right) \mathrm{W}$ in binding affinity and functional activity such as anti-cancer activity.

The aims of our study were to investigate whether further modifications of an antibody that has already undergone affinity-maturation could improve its binding affinity and subsequent efficacy and to develop a strategy for antibody improvement, using hu4D5 as a model system. Therefore, we generated random mutant libraries using an error-prone PCR method and degenerate random mutagenesis of $\mathrm{V}_{\mathrm{H}} \mathrm{V}_{\mathrm{L}}$ CDRs of hu4D5, and then the antibody variants with high affinity were isolated from the libraries using phage display. As a result, we successfully identified a variant with a 7.4-fold higher affinity and 7.2-fold greater antitumor activity compared to hu4D5. In addition, we speculate how the modifications in hu4D5 improve binding affinity using molecular modeling.

\section{MATERIALS AND METHODS}

\section{Construction of scFv libraries}

Phage-displayed scFv (a single chain variable fragment) librar- ies were constructed using a phagemid vector pCMTG (Oh et al., 2007) encoding the scFv-plll fusion protein. The structure of the vector is schematically shown in Fig. 1A. The scFv, comprising a light variable chain, a linker and a heavy variable chain was placed under the control of the lac promoter inducible by IPTG. The linker sequence was GGGGSGGGSGGSS.

A "stop template" version of the scFv display vector generated using stop codon TGA was used as a PCR template to prevent occurrence and enrichment of the template during the screening process.

Libraries LN01 and LN02 randomized at four positions of the CDR-H3 (\# 96, 97, 98 and 100) and at six positions of the CDR-H3 (\# 98, 100, 100b, 100c, 101 and 102), respectively, were generated by degenerate PCR. The phage-displayed LN01 and LN02 libraries were mixed, and a panning procedure was carried out. To generate the LN03 library, which was randomized at seven positions on CDR-L3, two sublibraries randomizing four positions on each (\#89, 90, 92, 93 and \#93, 95, $96,97)$ were generated using degenerate PCR and combined, and then the panning procedure was performed.

Degenerate PCR was performed using a Bio-Rad C1000 thermal cycler according to the manufacturer's instructions (Ex taq, Takara, Japan). The PCR conditions were as follows: denaturation, $95^{\circ} \mathrm{C}$ for $20 \mathrm{~s}$; annealing, $57^{\circ} \mathrm{C}$ for $30 \mathrm{~s}$; extension, $72^{\circ} \mathrm{C}$ for $45 \mathrm{~s} ; 27$ cycles. The PCR scheme and primer sets used in this study are shown in Fig. 1 and Table 1, respectively.

\section{Selection of HER2-specific variants from ScFv libraries}

The phagemid DNA libraries were introduced into E. coli XL1blue-MRF' (Stratagene, USA) by electroporation (Sidhu et al., 2000), and the transformants were infected with Ex12 helper phages (Back et al., 2002).

To screen out HER2-specific antibodies from the libraries, MaxiSorp immunotubes (Nunc, 444202) were coated with human HER2-ECD (extracellular domain of ErbB2 or p185HER2, fused with Fc; R\&D systems, USA). The libraries infected with Ex12 helper phage (IG therapy, Korea) were then used for panning according to the manufacturer's instruction.

Table 1. PCR primer sequences used for the library construction

\begin{tabular}{|c|c|c|c|c|}
\hline $\begin{array}{l}\text { No. of } \\
\text { Library }\end{array}$ & PCR templates & PCR purpose \& methods & $\begin{array}{l}\text { No. of primer } \\
\text { and direction }\end{array}$ & Primer sequences \\
\hline LN01 & $\begin{array}{c}\text { hu4D5 } \\
\text { (HFR4 } \mathrm{S}_{113} \text { changed } \\
\text { to stop codon TGA) }\end{array}$ & $\begin{array}{c}\text { Randomizing } 4 \text { positions of CDR-H3 } \\
(96,97,98,100) \\
\text { Random Degenerate }\end{array}$ & $\begin{array}{l}\text { 1. Forward } \\
\text { 2. Reverse }\end{array}$ & $\begin{array}{l}\text { AATTgagctcGATATCCAGATGACCCAGAG } \\
\text { AATTACTAGTGCTACTCACGGTCACCAGAGTTC } \\
\text { CCTGTCCCCAgtaatcatggcgtaMNNgccMNNMNNM } \\
\text { NNCCATCTAGAGCAGTAGTAC }\end{array}$ \\
\hline LN02 & $\begin{array}{c}\text { hu4D5 } \\
\text { (HFR4 } \mathrm{S}_{113} \text { changed } \\
\text { to stop codon TGA) }\end{array}$ & $\begin{array}{l}\text { Randomizing } 6 \text { positions of } \\
\text { CDR-H3 } \\
(98,100,100 \mathrm{~b}, 100 \mathrm{c}, 101,102) \\
\text { Random Degenerate }\end{array}$ & $\begin{array}{l}\text { 1. Forward } \\
\text { 3. Reverse }\end{array}$ & $\begin{array}{l}\text { AATTgagctcGATATCCAGATGACCCAGAG } \\
\text { AATTACTAGTGCTACTCACGGTCACCAGAGTTC } \\
\text { CCTGTCCCCAMNNMNNMNNMNNgtaMNNgccM } \\
\text { NNaccgccccatctagag }\end{array}$ \\
\hline \multirow[t]{2}{*}{ LN03 } & $\begin{array}{c}\text { hu4D5 } \\
\text { (LFR3 } \mathrm{C}_{88} \text { changed } \\
\text { to stop codon TGA) }\end{array}$ & $\begin{array}{c}\text { Two sub-libraries : each randomizing } \\
4 \text { positions of CDR-L3 } \\
(89,90,92,93 \text { and } 93,95,96,97) \\
\text { Random Degenerate }\end{array}$ & 4-1. Forward & $\begin{array}{l}\text { GACTTCGCTACGTACTACTGCNNKNNKcacNNK } \\
\text { NNKactcctccgacaTTCGGACAAGGCAC } \\
\text { GACTTCGCTACGTACTACTGCcaacagcactacNNK } \\
\text { actNNKNNKNNKTTCGGACAAGGCAC }\end{array}$ \\
\hline & & & 5. Reverse & AATTGCGCGCtactcacggtc \\
\hline
\end{tabular}


Table 2. Deduced sequences, anti-cancer activity and binding kinetics of representative variants (as lgG format) from each library at $25^{\circ} \mathrm{C}$. Residues were numbered according to Kabat and colleagues.

\begin{tabular}{|c|c|c|c|c|c|c|c|c|c|c|}
\hline \multirow[t]{2}{*}{ Library } & \multirow[t]{2}{*}{ Variants } & \multirow{2}{*}{$\begin{array}{l}\text { CDR-L2 } \\
(\# 50 \sim 56)\end{array}$} & \multirow{2}{*}{$\begin{array}{l}\text { CDR-L3 } \\
(\# 89 \sim 97)\end{array}$} & \multirow{2}{*}{$\begin{array}{l}\text { CDR-H3 } \\
(\# 95 \sim 102)\end{array}$} & \multicolumn{2}{|c|}{$\begin{array}{l}\text { Relative anti-tumor } \\
\text { activity : ratio of } \\
\mathrm{IC}_{50} \text { (hu4D5 / variant) } \\
\end{array}$} & \multirow{2}{*}{$\begin{array}{l}k_{\text {on }} \\
\left(10^{5} M^{-1} s^{-1}\right)\end{array}$} & \multirow{2}{*}{$\begin{array}{l}k_{\text {off }} \\
\left(10^{-4} s^{-1}\right)\end{array}$} & \multirow{2}{*}{$\begin{array}{l}\mathrm{K}_{\mathrm{D}} \\
(\mathrm{nM})\end{array}$} & \multirow{2}{*}{$\begin{array}{l}\text { Relative } \\
\text { affinity : } \\
\text { ratio of } \mathrm{K} \\
\text { (hu4D5) / } \\
\text { (variant) }\end{array}$} \\
\hline & & & & & SK-BR-3 & NCl-N87 & & & & \\
\hline- & hu4D5 & SASFLYS & QQHYTTPPT & WGGDGFYAMDY & $\begin{array}{c}1.0 \\
(0.9-4.5 \mathrm{nM})\end{array}$ & $\begin{array}{c}1.0 \\
(5.88 \mathrm{nM})\end{array}$ & 2.4 & 1.2 & 0.48 & 1.0 \\
\hline- & D98W & ----- & -- & ---W------ & 0.89 & 0.48 & 4.9 & 0.6 & 0.11 & 4.3 \\
\hline LN01 & $\mathrm{AH} 12$ & ----- & - & -H-V-M----- & 0.84 & ND & 2.5 & 2.8 & 1.12 & 0.4 \\
\hline LN02 & $\mathrm{AH} 06$ & ----- & ----- & ---W----FAL & 1.28 & 7.22 & 7.7 & 0.5 & 0.06 & 7.4 \\
\hline * & $\begin{array}{l}\text { Modified } \\
\text { AH06 D } \\
(\text { W98D) }\end{array}$ & --- & 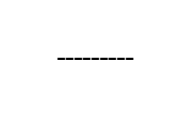 & -----FAL & 1.16 & 5.96 & 3.0 & 0.5 & 0.15 & 3.1 \\
\hline$* *$ & $\mathrm{AH} 16$ & ------ & -ב-- & -NAK---SFVH & 1.14 & 1.67 & 5.1 & 0.7 & 0.15 & 3.1 \\
\hline LN03 & AL07 & ------ & $----\mid-N I-$ & ------- & 0.87 & ND & 2.3 & 1.8 & 0.79 & 0.6 \\
\hline $\mathrm{C} 02$ & A058 & ------ & ----Q--AS & ---W----FAL & 1.02 & 2.79 & 2.2 & 2.3 & 1.05 & 0.5 \\
\hline
\end{tabular}

${ }^{*}$ To evaluate the effect of position 98 in $\mathrm{CDR}-\mathrm{H} 3$, W98 in $\mathrm{CDR}-\mathrm{H} 3$ of $\mathrm{AH06}$ was substituted with D98. ${ }^{* *}$ Direct engraftment of changed residues of CDR-H3 from the LN01 and LN02 libraries. CDR, complementarity-determining region; FR, framework; dashes indicate sequences identical to that of hu4D5. Values for $k_{\text {on }}$ and $k_{\text {off }}$ are measured at $25^{\circ} \mathrm{C}$ by SPR on BIAcore. The relative affinity, reported as $K_{D}$ (parent)/K $K_{D}$ (variant) indicates the fold increase in the binding affinity versus the parental antibody hu4D5. ND: not-determined.

The stringency of panning was controlled in a washing step and the plates were washed up to 20 times with TBS-T. After washing, 1.0-1.5 M ammonium thiocyanate was treated for 10 min, followed by washing with TBS-T (Macdonald et al., 1998; Wang et al., 2000).

\section{Screening and relative ELISA}

After three to five panning procedures, screening ELISA using soluble scFv-plll fusion molecules prepared from E. coli was performed as described previously (Song et al., 2009).

In the screening ELISA, human HER2-ECD or human IgG (Sigma) and anti-plll antibodies (MoBiTec, PSKAN3) were used as the coating antigen and detecting antibody, respectively. Consequently, we selected clones expressing phage-displayed scFv that bound to antigen-coated plates but not to IgG-coated plates.

To assess the relative binding of the soluble scFv fragment expressed in E. coli, an ELISA was performed with thiocyanate solution. After scFv incubation, $1 \mathrm{M}$ ammonium thiocyanate buffer was treated for $15 \mathrm{~min}$ at room temperature, followed by a washing step. The remaining steps were conducted as described (Song et al., 2009).

Phagemids extracted from the selected clones were analyzed by DNA sequencing, and then CDR were identified using NCBI lgBLAST (http://www.ncbi.nlm.nih.gov/igblast/).

\section{Cloning, transient expression and purification of the isolated variants}

The mammalian expression vector systems pOptiVEC (for heavy chain expression, Invitrogen, USA) and pcDNA3.3 (for light chain expression, Invitrogen, USA) were used to express the full-length lgG1 antibody. FreeStyle CHO-S cells (Invitrogen, USA) were transfected with the expression vector containing the antibody gene according to the manufacturer's protocol. Five days after transfection, the culture media were harvested and the $\operatorname{lgG}$ form of the antibody variant was purified using Mabselect (GE Healthcare, UK).

Inhibitory activity of cancer cell proliferation in vitro The HER2-positive breast cancer cell line SK-BR-3 (HTB-30, ATCC) and the gastric cancer cell line NCI-N87 (CRL-5822, ATCC) were purchased from ATCC and maintained in McCoy's 5a (Gibco BRL, USA) and RPMI-1640 (Gibco BRL, USA), respectively. The cells were seeded at a concentration of $7.5 \times$ $10^{3}$ cells/well, cultured at $37^{\circ} \mathrm{C}$ with $5 \% \mathrm{CO}_{2}$ overnight, and treated with the serially diluted antibodies the next day. After 6 days of treatment, viable cells were counted by a WST-8 cell proliferation assay (Japan), as described previously (Gong et al., 2004).

\section{SPR (surface plasmon resonance) analysis}

We used a surface plasmon resonance biosensor (BIAcore ${ }^{\mathrm{TM}}$ 2000 ) to detect antibodies against HER2-ECD. After immobilizing HER2-ECD molecules onto the surface of M5 sensor chips (GE Healthcare, USA), as described previously (Johnsson et al. 1991), at a level of approximately $90-130$ response units, serially diluted antibodies were injected with increasing concentrations (from $0.032 \mathrm{nM}, 0.16 \mathrm{nM}, 0.8 \mathrm{nM}, 4 \mathrm{nM}, 20 \mathrm{nM}$ to $100 \mathrm{nM}$ ) at a flow rate of $10 \mu \mathrm{l} / \mathrm{min}$ for $5 \mathrm{~min}$, followed by injection of a running buffer for $30 \mathrm{~min}$ to monitor dissociation. The equilibrium dissociation constant $K_{D}$ of the surface plasmon resonance was calculated as $\mathrm{k}_{\text {off }} / \mathrm{k}_{\text {on }}$.

Domain specificity analysis of the isolated variants to HER2-ECD antigen (indirect ELISA)

To determine the HER2 domain specificity of isolated variants, an ELISA was performed with recombinant $\triangle$ HER2-ECD, a partially deleted form of domain IV consisting of 562 amino acids from residue 22 to residue 584 of HER2 (Genentech Patent US6949245, 2005), fused with Fc or HER2-ECD fused 
A LN01

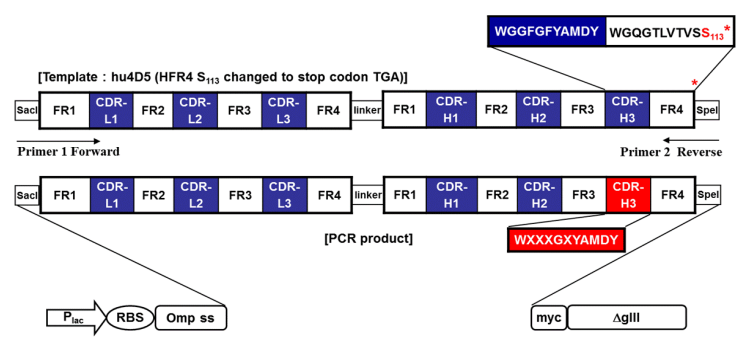

C LN03

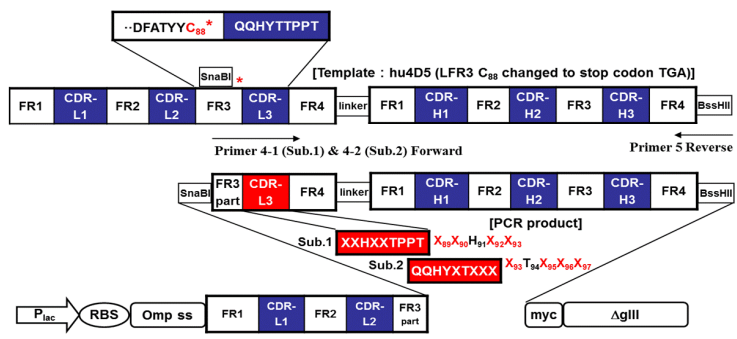

B LN02

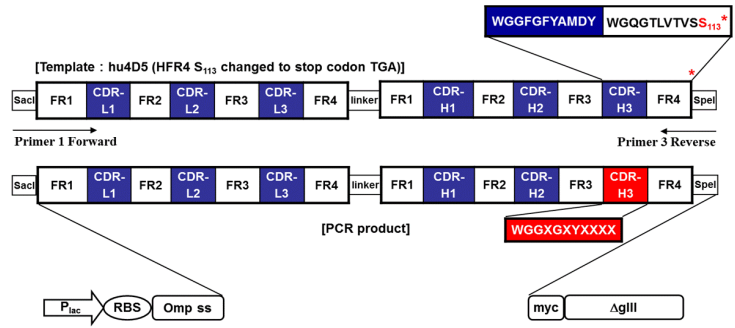

$\boldsymbol{D}$ Overall phagemid vector pCMTG

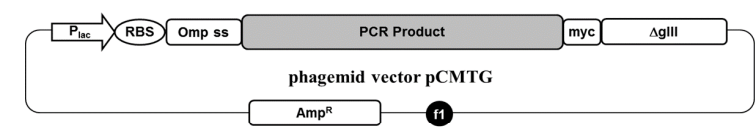

Fig. 1. Construction of pCMTG scFv expression vector (A) and schematic representation of randomized libraries LN01 (B), LN02 (C) and LN03 (D). Thin black arrows indicate the primers to construct each randomized library. The PCR template for LN01 and LN02 was a modified version that contained a TGA stop codon introduced at the S113 residue. For the PCR template for LN03, a TGA stop codon was introduced at the $\mathrm{C} 88$ residue. $\mathrm{X}$ denotes the replacement of a codon with the degenerate codon NNS. CDR residues are numbered according to Kabat and Wu. (1991).

with Fc (R\&D system, USA) as coating antigens. MaxiSorp 96well microtiter plates (Corning, USA) were coated with 0.5 $\mu \mathrm{g} / \mathrm{ml}$ of recombinant $\triangle \mathrm{HER} 2-\mathrm{ECD}$ fused with Fc or HER2ECD fused with Fc (R\&D system, USA).

After an overnight incubation at $4^{\circ} \mathrm{C}$, the plates were washed with TBS-T and blocked with $5 \%$ nonfat milk. Then, the plates were treated with the isolated antibody variants and incubated with HRP-conjugated anti-human kappa chain (Sigma, USA). An ELISA analysis was performed as described previously (Yoon et al., 2006).

Cross-reactivity analysis of the isolated antibody to other receptor tyrosine kinases (Indirect ELISA)

To analyze the cross-reactivity of the antibodies to receptor tyrosine kinases other than HER2, MaxiSorp 96-well microtiter plates were coated with $1 \mu \mathrm{g} / \mathrm{ml}$ of Fc-fused ECD of PDGFR $\beta$, VEGFR2, IGF-IR, FGFR3 (IIIc), EGFR, HER3 or HER4 (R\&D systems, USA) or $2 \mu \mathrm{g} / \mathrm{ml}$ of HGFR/c-Met ECD-Fc (R\&D systems, USA). After an overnight incubation at $4^{\circ} \mathrm{C}$, the plates were incubated with $30 \mathrm{nM}$ of the isolated antibody variants at $37^{\circ} \mathrm{C}$ for $2 \mathrm{~h}$.

After washing with TBS-T, the plates were treated with antigoat IgG-peroxidase antibody (Sigma, A5420) or anti-mouse IgG-peroxidase antibody (Sigma, A9044) at $37^{\circ} \mathrm{C}$ for $1 \mathrm{~h}$. ELISA analysis was performed as described previously (Yoon et al., 2006).

\section{Inhibitory effect of the isolated variants to HER2 signaling (Immunoblot)}

The NCl-N87 cells were seeded at a concentration of $2 \times 10^{5}$ cells $/ \mathrm{ml}$ into a $100-\mathrm{mm}$ cell culture dish, treated with $10 \mu \mathrm{g} / \mathrm{ml}$ of antibodies for $16 \mathrm{~h}$ to analyze pAkt and $72 \mathrm{~h}$ to analysis p27, and lysed by adding RIPA buffer (1.0\% NP-40, $0.5 \%$ deoxycholic acid, $0.1 \%$ SDS, $50 \mathrm{mM}$ Tris- $\mathrm{HCl}, \mathrm{pH} 8.0$ ) with $1 \mathrm{mM}$ EDTA, 1 mM PMSF, protease inhibitor cocktail (Thermo, USA) and phosphatase inhibitor cocktail (Thermo, USA). Western blot analysis was performed as described previously (O'Brien et al., 2010).

Computing the stability and analyzing antibody-antigen interaction

To analyze the molecular interactions between the antibody and HER2 (P04626, UniProtKB), we obtained the structural information for HER2 and hu4D5 from the PDB (code: 1N8Z; web site: http://www.rcsb.org/pdb/home/home.do). The effects of mutations in the antibody variable regions on stability, force field and charges were estimated using CHARMm module and Momany-Rone, respectively (Discovery Studio 3.5, Accelrys Inc., USA, http://accelrys.com/). Data on intraprotein interactions were obtained from the Protein Interactions Calculator (http://pic.mbu.iisc.ernet.in/), and the binding energy between the antibody and HER2 molecule was calculated by equation 1 below.

All the experiments were carried out on a $3.40 \mathrm{GHz}$ Intel Core i7 Quard-Core processor. Molecular modeling was performed using the Macromolecules modules on Discovery Studio 3.5 (Accelrys Inc.), and CHARMm (ver. 36.2) was used for energy minimization.

Equation 1. Binding energy of antibody and antigen HER2 $\Delta G^{\text {HER2:VHNL binding energy }}=\Delta G^{\text {HER2NHNL energy }}-\left(\Delta G^{\text {HER2 energy }}+\Delta G\right.$ VHNL energy 


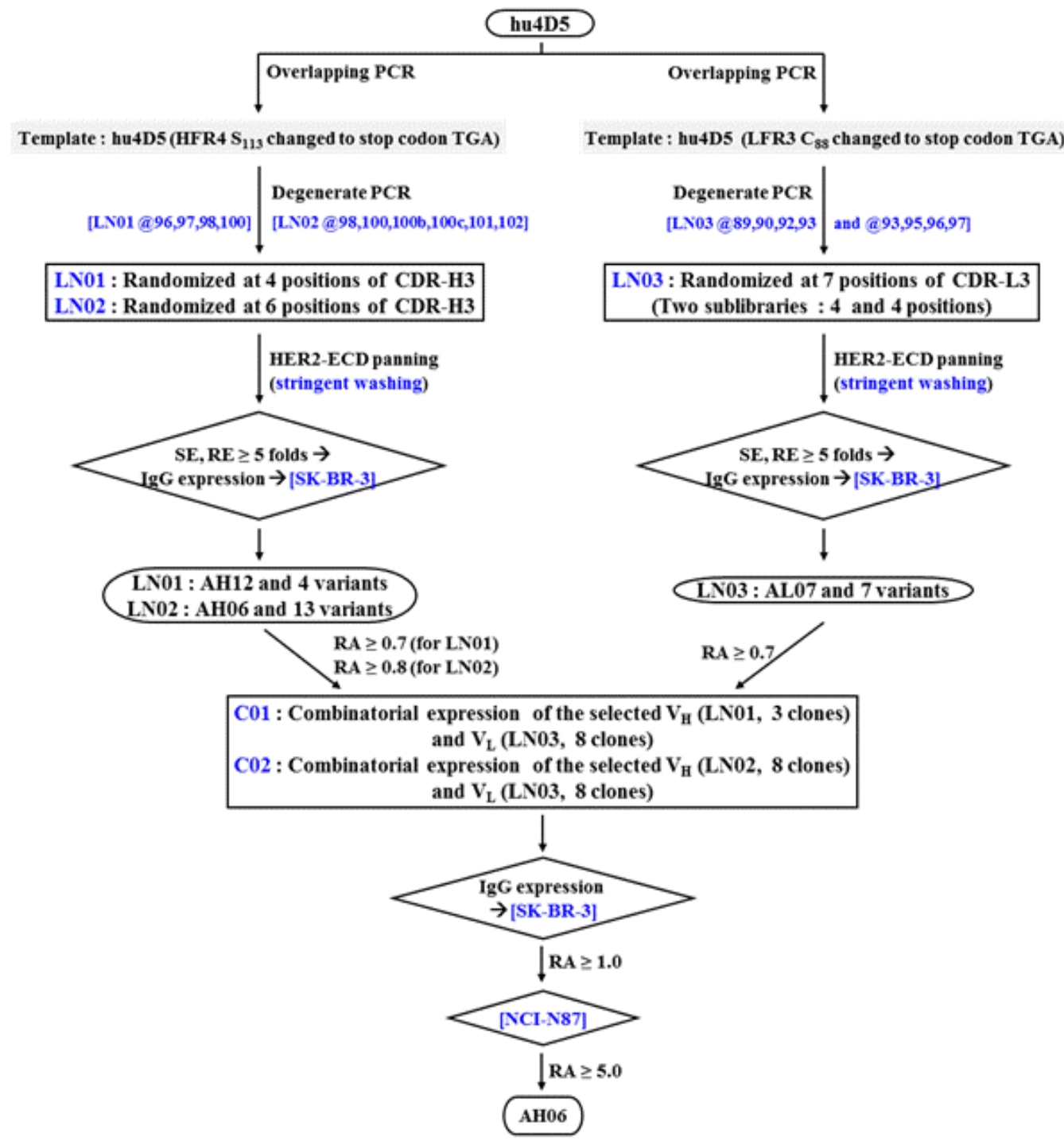

Fig. 2. Candidate screening flow scheme. ELISA units and anti-proliferative activity against tumor cells were considered in selecting variants. The variants whose SE and RE values were 5-fold higher than those of the negative blank were selected. Then, further selection proceeded based on RA as indicated. SE, Screening ELISA unit of $\mathrm{OD}_{450}$; RE, Relative ELISA unit of $\mathrm{OD}_{450}$; RA (Relative activity), a ratio of IC 50 of parent hu4D5 to the variant in anti-proliferative activity against breast tumor SK-BR-3 or gastric tumor NCI-N87 cells.

\section{RESULTS}

\section{Construction of variants scFv libraries}

Because the parent antibody hu4D5 had high affinity $\left(K_{D}\right.$ value of $0.54 \mathrm{nM}$, Table 2), it was difficult to identify an antibody with improved affinity using a general panning method. We were also concerned that the tight-binding "contaminant (parent or template antibody, hu4D5)" scFv might be dominantly selected because the parent antibody hu4D5 is an extremely tightbinding antibody. Thus, the template for each library was a modified version of phagemid, with a stop codon (TGA) introduced at an upstream or downstream position where the amino acid was to be mutated by the overlapping PCR method. A different position introducing a stop codon for each library is as follows: the S113 position of HFR4 in CDR-H3 for the LN01 and
LN02 libraries and the C88 position in CDR-L3 for the LN03 library (Fig. 1).

To minimize the library size and number of constructions, we primarily excluded CDR-H1, CDR-L1, and CDR-H2, which consisted of $5,10,17$ and 7 residues, respectively. However, the strategy for site-directed random mutagenesis of all the CDR residues, including CDR-H3 (Kabat No. \#95 102, 11 amino acid residues, $\left.W_{95} G_{96} G_{97} D_{98} G_{99} F_{100} Y_{100 a} A_{100 b} M_{100 c} D_{101} Y_{102}\right)$ and CDR-L3 (Kabat No. \#89 97, 9 amino acid residues, $\mathrm{Q}_{89} \mathrm{Q}_{90} \mathrm{H}_{91}$ $\left.\mathrm{Y}_{92} \mathrm{~T}_{93} \mathrm{~T}_{94} \mathrm{P}_{95} \mathrm{P}_{96} T_{97}\right)$, is practically impossible because the theoretical diversity of each library is $2 \times 10^{14}$ and $5 \times 10^{11}$, respectively, which is too large to construct the libraries.

To design a library with a suitable size for efficient screening, the CDR-L3 H91, CDR-H3 W95 and CDR-H3 Y100a positions (Gerstner et al., 2002), previously reported to be the most criti- 


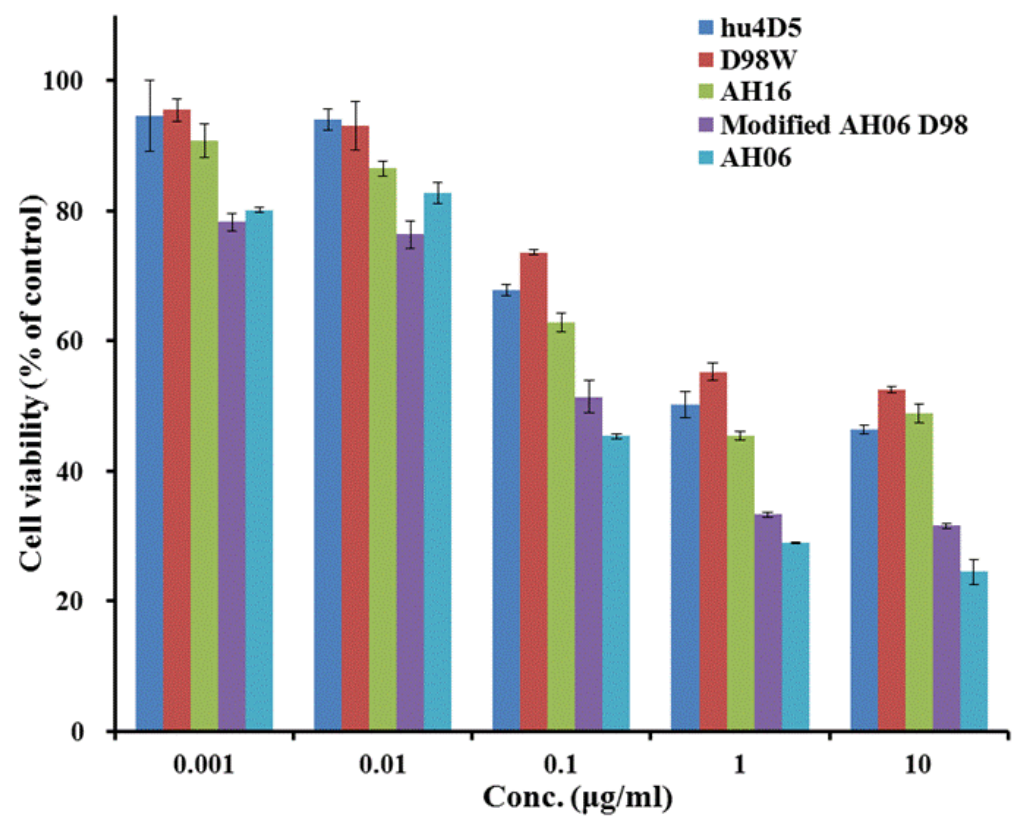

Fig. 3. Inhibitory effects of hu4D5 variants in $\mathrm{NCl}-\mathrm{N} 87$ cell proliferation. Cells were treated with the indicated concentrations of variants for 6 days. Cell viability is expressed as a percentage relative to the untreated control. Data represent the average \pm SD of three experiments. The cell growth inhibitory activity against $\mathrm{NCl}-\mathrm{N} 87$ of AH06 $\left(\mathrm{IC}_{50} 0.12 \mu \mathrm{g} / \mathrm{ml}=0.81 \mathrm{nM}\right)$ was increased 7.2 times compared with the parental antibody hu4D5. cal to antigen binding key residues, were excluded from randomization. G99 (90\% or $100 \%)$ in CDR-H3 and T94 (45\%) in CDR-L3 were conserved at frequencies higher than $45 \%$ after screenings from the random mutagenesis library and were also excluded from randomization. Although F100 in CDR-H3 was conserved with a frequency $52 \%$ (Gerstner et al., 2002), the F100 position, shown to play a role in the antigen-antibody interface (Kelley et al., 1993), was designated as a target site for randomized library construction.

In conclusion, a total of 5 residues consisting of key residues (CDR-L3 H91, CDR-H3 W95 and CDR-H3 Y100a) and relatively invariant residues (CDR-H3 G99 and CDR3 T94) were excluded from randomization in the library construction. Libraries targeting CDR-H3 and CDR-L3, with the exception of the 5 residues described above, were constructed using an NNK codon ( $\mathrm{N}=\mathrm{A}, \mathrm{G}, \mathrm{T}$ or $\mathrm{C} ; \mathrm{K}=\mathrm{G}$ or $\mathrm{T}$ ) in 3 divided subgroups. CDR-H3 and CDR-L3 targeting the LN01, LN02 and LN03 libraries were constructed according to the mutagenesis strategy, and the diversities of each library were $9.7 \times 10^{7}, 1.5 \times 10^{8}$ and $3.7 \times 10^{8}$, respectively.

\section{Selection of HER2-specific variants from scFv libraries}

After library construction, we screened variants in accordance with the strategy described in Fig. 2. High-stringency screening to select an antibody with a higher affinity than the parent antibody hu4D5 was performed as follows. First, washing was carried out for up to 44 hours to select an antibody exhibiting an enhanced off-rate (Chen et al., 1999). Second, a pre-elution was performed with $0.1 \mathrm{M}$ glycine $(\mathrm{pH} 2.2)$ before the final elution (Chen et al., 1999). Third, weakly bound antibodies were removed by treating with ammonium thiocyanate before elution (Macdonald et al., 1998; Wang et al., 2000). The washing step was performed with $0.1 \mathrm{M}$ glycine $(\mathrm{pH} 2.2)$ and $1 \mathrm{M}$ ammonium thiocyanate in any order during three to five rounds of panning.

Finally, the antibodies with high affinity were enriched during successive rounds of panning by decreasing the concentration of HER2 ECD-Fc from 2.0 to $0.1 \mu \mathrm{g} / \mathrm{ml}$. If the number of colonies from a negative antigen (human IgG or BSA) after panning was less than $1 \%$ of that of HER2, we proceeded with the screening.

Because the primary purpose of this study was to improve the biological activity of the antibody, the ratio or fold increase of the variants to hu4D5 in anti-proliferative activity was calculated as $\mathrm{IC}_{50}$ of hu4D5 / IC 50 of variant. We planned to select the variants with a ratio of 1 or more in their activity against SK-BR3 cells as a candidate for a biobetter antibody.

All 5, 9 and 13 variants derived from LN01, LN02 and LN03, respectively, failed to meet the criterion, except the variant AH06 from LN02 (a ratio of 1.3 for SK-BR-3 cells). Because the substitution occurred in either CDR-H3 or L3, we further investigated whether a combination of CDR substitutions could increase the anti-proliferative activity.

To generate combinatorial variants by shuffling the variants from LN03 with randomized $V_{L}$ and the variants from LN01 or LN02 with randomized $\mathrm{V}_{\mathrm{H}}$, we selected 3,8 , and 8 variants whose activity ratio for SK-BR-3 cells was more than $0.7,0.8$ and 0.7 from LN01, LN02 and LN03, respectively.

Two series of the combinatorial expression of heavy and light chain variants, $\mathrm{C01}$ (CDR-H3 variants from LN01 and CDR-L3 variants from $\mathrm{LNO} 3$ ) and $\mathrm{CO} 2$ (CDR-H3 variants from $\mathrm{LNO} 2$ and CDR-L3 variants from LNO3) were implemented by transient expression in $\mathrm{CHO}-\mathrm{S}$ cells (Fig. 2).

In $\mathrm{C} 01$, a total of 24 variants by the combination of three CDR-H3 variants from LN01 and eight CDR-L3 variants from LNO3 were expressed transiently in CHO-S cells. Twenty-three variants were purified and their anti-proliferative activity against SK-BR-3 cells was assessed. However, there were no variants with an activity ratio of 1.0 or more.

In $\mathrm{C} 02$, a total of 64 variants of the combination of eight CDR-H3 variants from LNO2 and eight CDR-L3 variants from LN03 were expressed transiently in CHO-S cells. As a result of measuring the anti-proliferative activity of $58 \mathrm{lgGs}$ selected from C02 against SK-BR-3 cells, there were 15 variants with an activity ratio of 1.0 or more. There were no variants with significantly enhanced anti-cancer activity compared with AH06 derived from $\mathrm{LN} 02$.

Several variants, such as AH06, selected from a total of 109 variants, were further tested for anti-cancer activity against the 

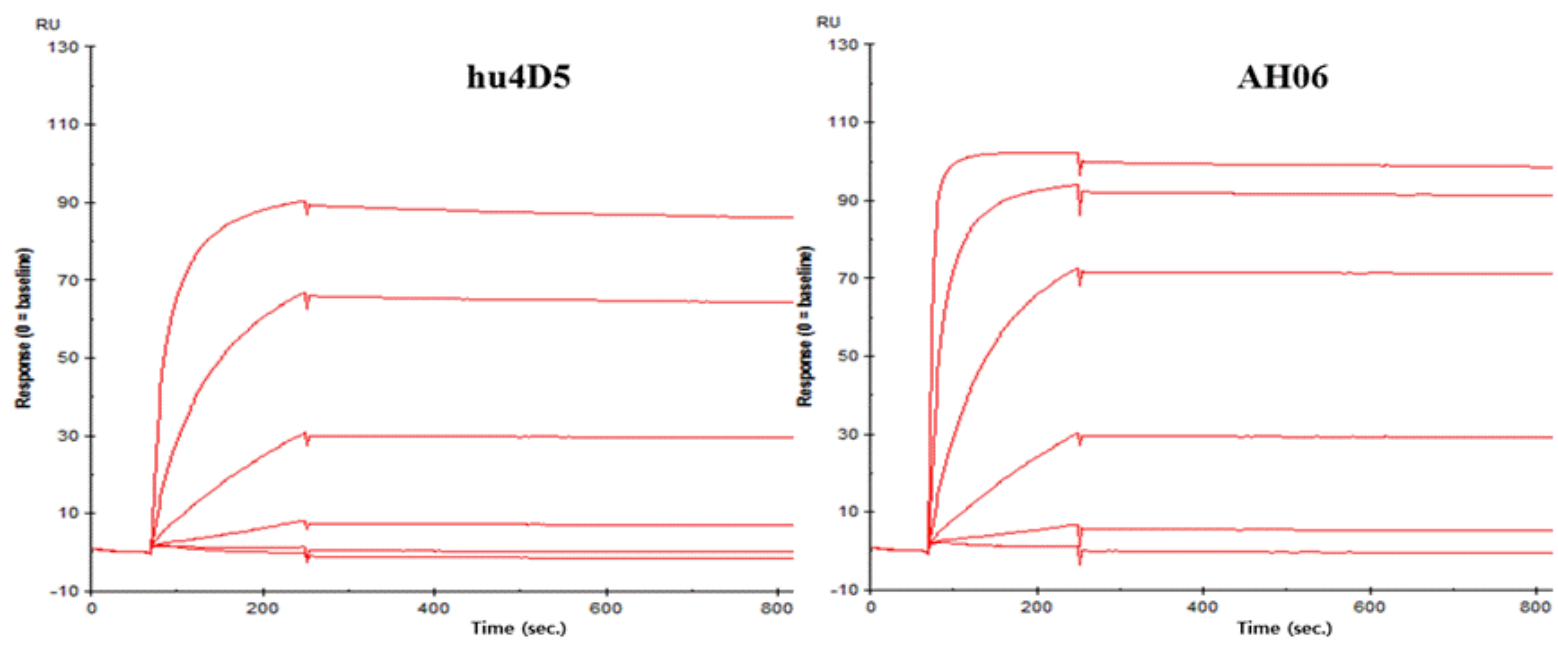

Fig. 4. SPR binding analysis of isolated variants to immobilized human HER2-ECD. Antibody variants were injected at six different concentrations, $0.032 \mathrm{nM}, 0.16 \mathrm{nM}, 0.8 \mathrm{nM}, 4 \mathrm{nM}, 20 \mathrm{nM}$ and $100 \mathrm{nM}$, over a surface on which $100 \mathrm{RU}$ of HER2-ECD had been coupled. The parameters solved for each run are shown in Table 2. AH06 has a 7.4-fold improved affinity, reaching a $K_{D}$ of $60 \mathrm{pM}$, compared to that of the parent, hu4D5 $\left(K_{D} 0.48 \mathrm{nM}\right)$. The $X^{2}$ values of the fitted curves were $<1$.

HER2-positive gastric cancer cell line NCl-N87 and binding affinity using Biacore ${ }^{\mathrm{TM}}$.

\section{Inhibitory effects on cell proliferation and the binding affinity of $\mathrm{AHOG}$}

The variant $\mathrm{AH} 06$, which had a 7.2-fold enhanced antiproliferative activity against $\mathrm{NCl}-\mathrm{N} 87$ cells (Fig. 3 ) in comparison to hu4D5, was derived from the library LN02, has an unchanged light chain and a substituted heavy chain with changes in D98W, M100cF, D101A, and Y102L of CDR-H3. AH06 also showed substantially enhanced binding affinity. The affinity of $\mathrm{AHO6}$ was 7.4 -fold and 2.4-fold higher compared to those of the parent hu4D5 and D98W, the previously reported variant (Gerstner et al., 2002), respectively (Table 2 and Fig. 4).

Because it has been reported that $\mathrm{D} 98 \mathrm{~W}$, which contains the substitution of Glu for Trp at position 98 in CDR-H3, has a binding affinity approximately 3 times higher than that of hu4D5 (Gerstner et al., 2002), a modified version of AH06 (AH06 W98D), in which Trp was substituted with Glu at position 98, was constructed to evaluate whether the mutation has any impact.

The binding affinity of AH06 W98D was also 3.1 times higher than that of hu4D5, suggesting that the change in the sequence of "F100c A101 L102" contributes to the improvement in its binding affinity of 3.1 -fold for the HER2-ECD molecule. The binding affinity of D98W was improved 4.3-fold, whereas AH06 showed a 7.4-fold higher binding affinity than hu4D5 (Table 2; Fig. 4), which suggests that W98 and the F100c A101 L102 sequence synergistically improve the binding affinity.

\section{Domain specificity against the HER2 molecule and} cross-reactivity to other receptor tyrosine kinases of the AHO6

The binding ELISA showed that the variant $\mathrm{AH} 06$ was capable of binding to domain IV of the HER2 antigen, similar to hu4D5 (Fig. 5A). In addition, AH06 did not bind to any other RTKs (EGFR, HER2, HER3, HER4, PDGFR 3 , VEGFR2, IGF1R,
FGFR3 and HGFR) (Figs. 5B and 5C), indicating that it is highly specific to the HER2 antigen.

\section{Effects of the AH06 on downstream signaling of HER2}

To investigate the inhibitory mechanism of $\mathrm{AH} 06$ against HER2 signaling in the gastric cancer cell line $\mathrm{NCl}-\mathrm{N} 87$, the protein levels, including HER2, phosphorylated HER2 (pHER2), Akt, phosphorylated Akt (pAkt) and p27, were examined by western blot analysis (Fig. 6). Phosphorylation of HER2 and AKT were inhibited without a change in protein expression of HER2 and Akt by treatment of hu4D5 as well as AH06.

On the other hand, the expression level of the cyclindependent kinase inhibitor p27 was greatly increased when cells were treated with AH06. These results suggest that the AH06 antibody inhibits activation of the PI3K-Akt signaling pathways via HER2 and induces cell death by increasing the expression of p27. Thus, cell-context dependent induction of p27 might contribute to cellular susceptibility to AH06.

\section{Computing stability and analyzing antibody-antigen} interactions

To analyze the binding modes and binding energies of the 4 changed residues (W98, F100c, A101 and L102) of AH06 to its antigen HER2 (P04626, UniProtKB), we used molecular modeling methodology and Equation 1. AH06 had a higher binding affinity for HER2 as well as lower binding energy compared to hu4D5 (Table 3), suggesting that AH06 could bind to HER2 more stably than did hu4D5.

Next, we investigated which of the 4 residues (W98, F100c A101 and L102) of AH06 contributed to the increase in binding affinity and binding energy. The substitution with $\mathrm{W}$ at position 98 increased the binding affinity and decreased the binding energy, suggesting that W98 plays a significant role in binding to HER2.

The binding affinity of "modified AH06" was approximately 3fold higher than that of hu4D5. However, unexpectedly there was no significant improvement in the binding energy of "modified AH06" compared to that of hu4D5. 
$\boldsymbol{A}$

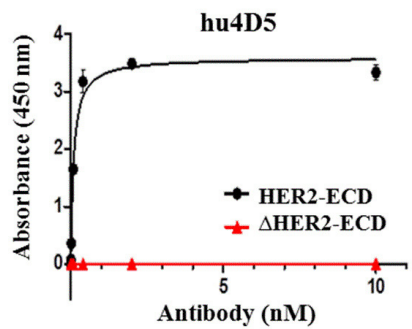

$\boldsymbol{B}$

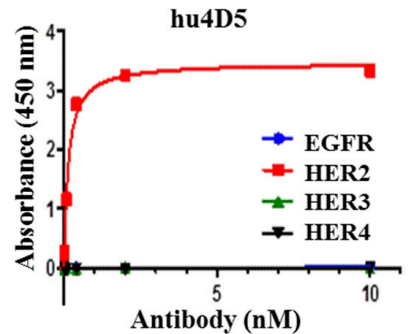

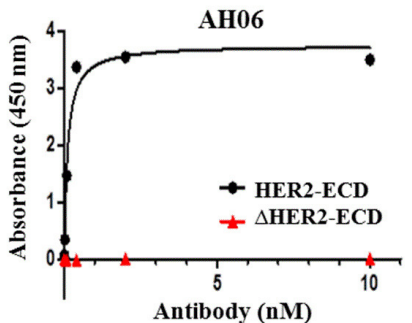

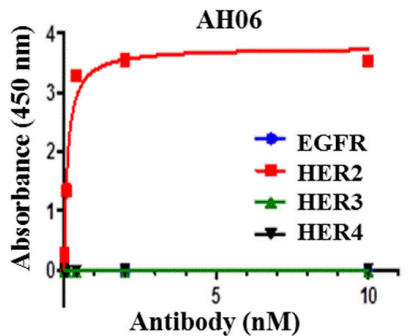

\section{C}
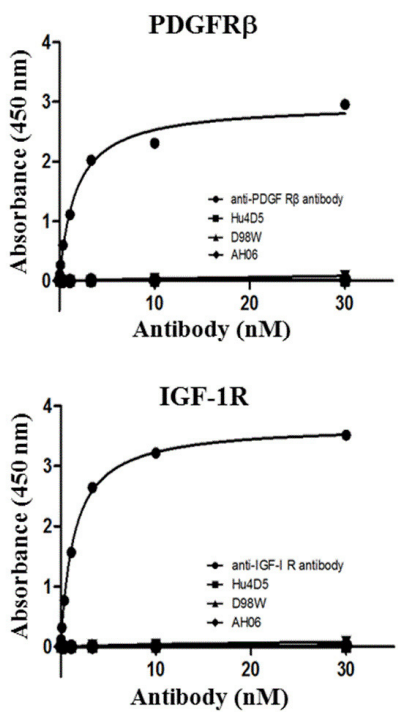
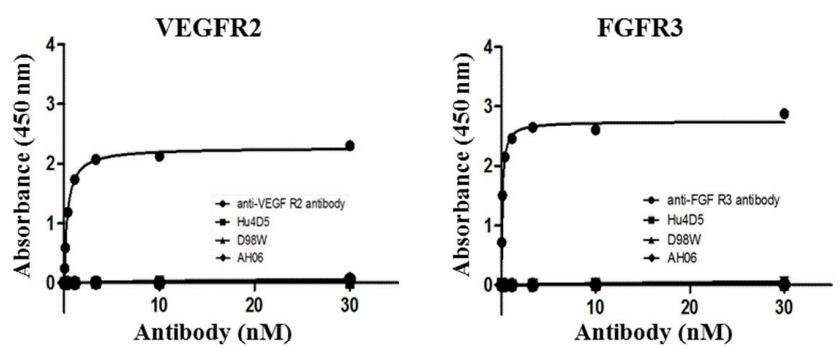

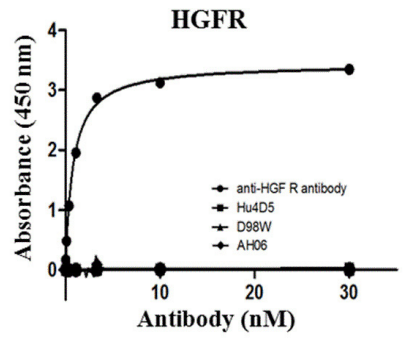

Fig. 5. ELISA assay. (A) Domain specificity of the antibody against HER2. Cross-reactivity of the antibody to the HER family (B) and receptor tyrosine kinase family (C). Antigens were immobilized in each well and incubated with various concentrations of antibodies. Bound antibody was detected using anti-human IgG conjugated to HRP. AH06 specifically bound to HER2, particularly its domain IV.

Analysis of the binding affinity and binding energy of the CDR-H3 variants indicates that the 3 residues F100c, A101 and L102 of AH06 can enhance the binding affinity to HER2 (by additional hydrophobic interactions) approximately 3-fold; however, W98 of CDR-H3 has the greatest impact. These results suggested that the residues W98, F100c, A101 and L102 of $\mathrm{CDR}-\mathrm{H} 3$ of $\mathrm{AH} 06$ exert synergistic effects on the binding affinity to HER2 and the binding energy.

To elucidate our experimental data, we simulated and analyzed the binding modes of hu4D5 and AH06 to HER2 using molecular modeling. The residues F100c, A101 and L102 of $\mathrm{CDR}-\mathrm{H} 3$ of $\mathrm{AH} 06$ were located at the $\mathrm{V}_{\mathrm{H}}-\mathrm{V}_{\mathrm{L}}$ interface. Because these 3 residues were located several Ås away from the HER2 residues (Fig. 7A), it is unlikely that the residues directly interact with HER2 antigen.

It was demonstrated that there could be a direct hydrophobic interaction between the aromatic ring group of the tryptophan residue (W98) of $\mathrm{AHO6}$ and the aliphatic group of the isoleucine (1613) residue located in domain IV of HER2 as well as the heavy and light chain hydrophobic interactions between the phenyl ring of $\mathrm{F} 100 \mathrm{c}$ in $\mathrm{CDR}-\mathrm{H} 3$ and the hydrophobic groups that is consist of Y36, P44 and F98 located in $V_{L}$ (Fig. 7B). On the other hand, there was no significant interaction between residue D98 of hu4D5 and the isoleucine (1613) residue in the aliphatic group located in domain IV of HER2 (Figs. 7C and 7D). Therefore, we speculated that these two types of interactions 


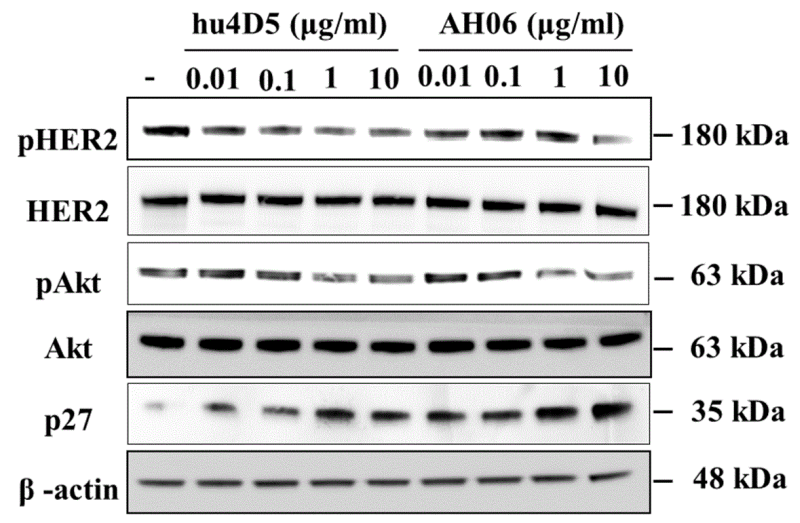

Fig. 6. Effects of the parent antibody hu4D5 and AH06 on HER2 signaling. Protein levels of HER2, pHER2, Akt, pAkt and p27 were assessed in NCl-N87 gastric cancer cells after antibody treatment for $16 \mathrm{~h}$ to analyze pHER2, HER2 and pAkt and $72 \mathrm{~h}$ to analyze p27 by Western blot. The $\beta$-actin was used as a loading control.

between the W98 and F100c and A101 and L102 could have a synergistic effect on the increased binding affinity to HER2.

\section{DISCUSSION}

Antibody affinity maturation by phage display is a highly efficient way of developing therapeutic antibodies (Lowe et al., 2012). Gerstner et al. chose 19 surface-exposed residues, including 12 residues of CDR-H and 7 residues of CDR-L, known to be located in the areas directly contacting HER2, and constructed randomized Fab libraries targeting these residues. They chose and combined 5-7 residues, including 2-4 residues from $\mathrm{CDR}-\mathrm{H}$ and 1-3 residues from CDR-L per library and randomized all these residues at the same time (Gerstner et al., 2002).

In contrast to previous studies, we choose 6 residues at positions \#98, 100,100b, 100c, 101 and 102 of CDR-H3 and randomized those 6 residues simultaneously. In addition, because it has been reported that binding affinity can be increased by a combination of mutations isolated from separate libraries (Schier et al., 1996), we randomized the residues within either CDR-H3 or CDR-L3, panned each library, and selected the variants based on their anti-cancer activities. Then, the selected variants were cloned into the expression vectors pOptiVEC (for heavy chain expression) or pcDNA3.3 (for light chain expression). An additional diverse antibody repertoire was achieved by a combination of heavy and light chains, and the resulting IgG antibodies with substituted residues in both the heavy and light chains were expressed in CHO-S cells and finally evaluated on their anti-cancer activity (step-by-step screening scheme, Fig. 2).

We used a step-by-step rather than one-step strategy to efficiently randomize both CDR-H and CDR-L without difficulty in determining the position and the number of residues for randomization. Such a substitution of both CDR-H and CDR-L was expected to further improve the binding affinity as well as the functional activity of the antibody.

Contrary to our expectations, the HER2-binding affinity of A058, which was substituted with W98, F100c, A101, and L102 in $\mathrm{CDR}-\mathrm{H} 3$ (identical to $\mathrm{AH} 06$ ) and had 3 residues substituted with Q93, A96 and S97 in CDR-L3, was reduced to half that of hu4D5, although its anti-tumor activity against SK-BR-3 was similar to that of hu4D5. Therefore, the data suggest that the modification of CDR-L3 may be unable to largely contribute to the increase in HER2-binding affinity.

Nevertheless, AH06, with its 7.4-fold increase in binding affinity, was generated from LN02, which randomized 6 residues at positions \#98, 100, 100b, 100c, 101 and 102 of CDR-H3 at a time. Consistent with our conclusion, it has been reported that the binding affinity of antibodies is increased by the substitutions of CDR-H3 residues, such as the 100c, 101 and 102 positions (Phumyen et al., 2012; Rajpal et al., 2005).

In addition, as Gerstner et al. (2002) mentioned, a role of W98 of CDR-H3 in HER2 binding is unclear. Here we provide a possible explanation for that using modeling analysis regarding improvement of binding affinity of $\mathrm{AH} 06$. The simulation modeling suggested direct hydrophobic interactions between the aromatic ring group of tryptophan residue (W98) of AH06 and the aliphatic group of isoleucine (1613) residue located in the domain IV of HER2, and also between the phenyl ring of F100c in CDR-H3 and the hydrophobic groups that consist of $\mathrm{Y} 36$, P44 and F98 located in $V_{L}$ (Fig.7).

We speculate that the hydrophobic interactions between the heavy and light chain within $\mathrm{AH} 06$, induced by the substitution of the residues F100c, A101 and L102 of CDR-H3, could help increase the binding affinity, though not as strongly as W98. Our speculation is supported by studies reporting that residues that do not interact or contact antigen directly influence the interaction between the heavy and light chain, and thus increase binding affinity (Chatellier et al., 1996; Hawkins et al., 1993).

Table 3. Binding energies and affinities of AH06 and hu4D5. AH06 had a higher binding affinity for HER2 as well as a lower binding energy, compared to hu4D5.

\begin{tabular}{|c|c|c|c|c|}
\hline A. Binding energy & $\Delta \mathrm{G}^{\mathrm{HER} 2 \mathrm{NHNL}}$ & $\Delta \mathrm{G}^{\mathrm{HER} 2}$ & $\Delta \mathrm{G}^{\mathrm{VH} / \mathrm{LL}}$ & $\Delta \mathrm{G}^{\mathrm{HER} 2 \mathrm{VH} N \mathrm{~L}}$ \\
\hline hu4D5 & -19716.1 & -12050.6 & -7374.3 & -291.2 \\
\hline Modified AH06 & -19394.5 & -12050.5 & -7052.0 & -292.0 \\
\hline $\mathrm{AH} 06$ & -19432.8 & -12050.7 & -7065.2 & -316.9 \\
\hline \multicolumn{5}{|c|}{ B. Binding affinity (Biacore) } \\
\hline Antibody & $\mathrm{K}_{\mathrm{a}}(1 / \mathrm{Ms})$ & $\mathrm{K}_{\mathrm{d}}(1 / \mathrm{s})$ & $\mathrm{K}_{\mathrm{D}}(\mathrm{M})$ & $\Delta \mathrm{G}(\mathrm{kcal} / \mathrm{mol})$ \\
\hline hu4D5 & $2.4 \times 10^{5}$ & $1.2 \times 10^{-4}$ & $0.48 \times 10^{-9}$ & -291.2 \\
\hline Modified AH06 & $3.0 \times 10^{5}$ & $0.5 \times 10^{-4}$ & $0.15 \times 10^{-9}$ & -292.0 \\
\hline $\mathrm{AH} 06$ & $7.7 \times 10^{5}$ & $0.5 \times 10^{-4}$ & $0.06 \times 10^{-9}$ & -316.9 \\
\hline
\end{tabular}

hu4D5, CDR-H3 D98, M100c, D101, Y102; modified AH06, CDR-H3 D98, F100c, A101, L102; AH06, CDR-H3 W98, F100c, A101, L102 

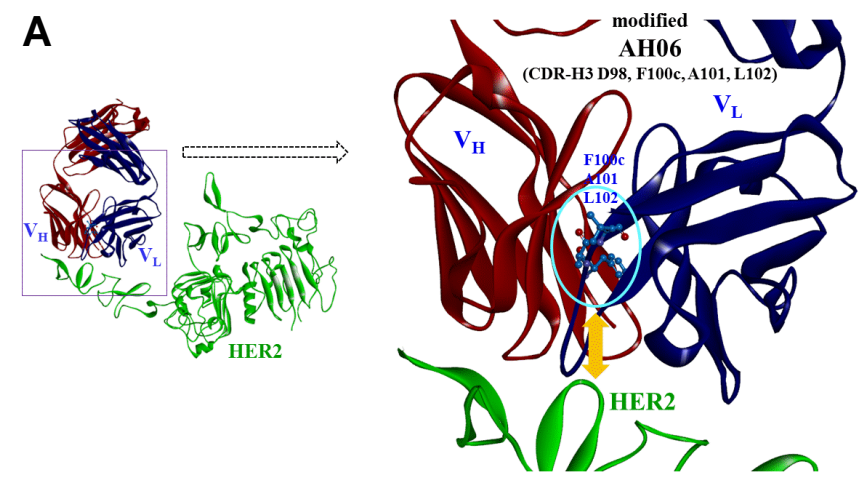

B

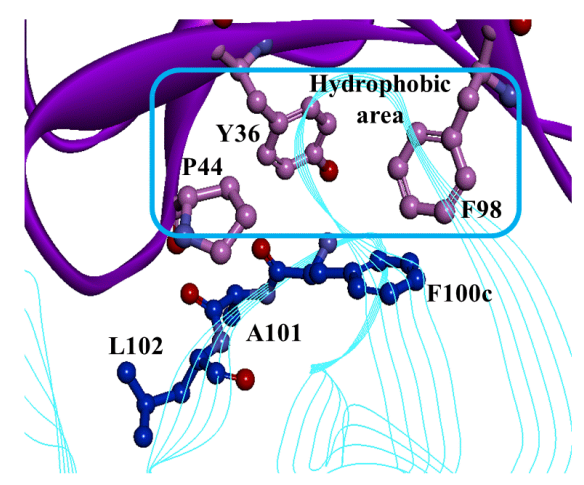

C
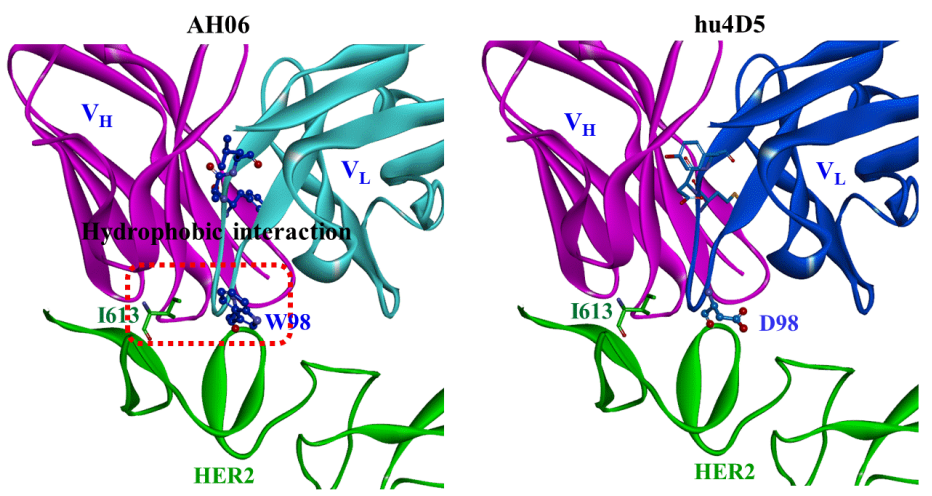

D

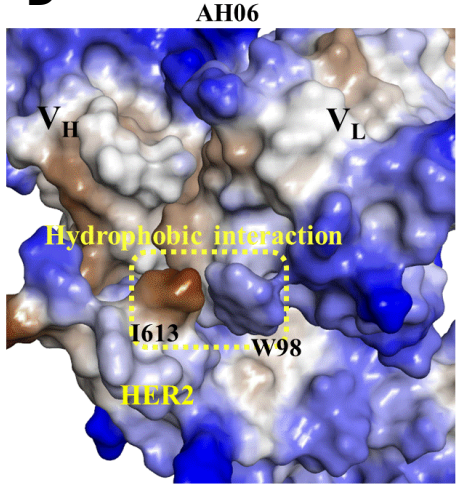

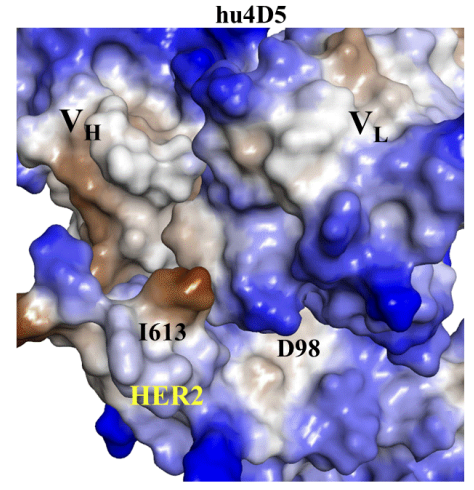

Fig. 7. Molecular interaction models of $\mathrm{AH} 06$ and hu4D5 complex with HER2. (A) A distance between three residues, F100c, A101 and L102 of modified AH06 (blue circle) and HER2 molecule (green). The residues F100c, A101 and L102 of CDR-H3 of AH06 were located in the region of $V_{H}-V_{L}$ interface. The $V_{H}$ domain and $V_{L}$ domain are colored with red and blue, respectively. (B) Molecular interactions between $V_{H}$ and $V_{L}$. The $V_{H}$ domain and $V_{L}$ domain are colored with pink and light blue. The residues F100c, A101 and L102 of CDR-H3 and Y36, P44 and F98 of $V_{L}$ were located in the region of $\mathrm{V}_{\mathrm{H}}-\mathrm{V}_{\mathrm{L}}$ interface. It was simulated that there could be a direct hydrophobic interaction between the phenyl ring of F100c in CDR$\mathrm{H} 3$ and the hydrophobic groups that is consist of $Y 36$, P44 and F98 located in $V_{L}$. (C) Ribbon model : The mutated region of variants is presented as a red square. (D) Surface model : The mutated region of variants is presented as a yellow square. (brown : hydrophobic, blue : hydrophilic). It was simulated that there could be a direct hydrophobic interaction between the aromatic ring group of tryptophan residue (W98) of AH06 and the aliphatic group of isoleucine (I613) residue located in the domain IV of HER2 as well as the heavy and light chain hydrophobic interactions by the residues F100c, A101 and L102 of CDR$\mathrm{H} 3$ 
Since Herceptin has been widely and mainly used in breast cancer treatment, we screened and evaluated the anti-cancer proliferative activity of the antibody variants in breast cancer cell line SK-BR-3 first, and then in gastric cancer cell line NCI-N87. However, it would have been possible to get better clones, if the antibody variants had been screened in $\mathrm{NCl}-\mathrm{N} 87$ first or coscreened in NCl-N87 and SK-BR-3 cells.

Although $\mathrm{AHO6}$ with the strongest binding affinity showed the most effective anti-proliferative activity, our data (Table 2) did not show a direct correlation between antigen binding affinity of antibody and its biological activity. However, it is consistent with the report that the anti-proliferative activity of humAb4D5 variants against HER2 overexpressing SK-BR-3 cells is not simply correlated with their binding affinity for the HER2 (Carter et al., 1992): the variant humAb4D5-3 with a binding affinity similar to that of humAb4D5-2 had a significantly enhanced antiproliferative activity compared to humAb4D5-2.

AH06 showed an 7.2-fold enhanced anti-proliferative activity against NCl-N87 gastric cancer cells compared to hu4D5, although it did not greatly enhance the activity against SK-BR-3 breast cancer cells. HER2 gene amplification is higher in $\mathrm{NCl}$ N87 compared with SK-BR-3: the HER2 amplification ratios relative to CEP17 were 8.4 and 4.9 in NCl-N87 and SK-BR-3 cells, respectively (Kim et al., 2008), and receptor/ligand avidity generally increases with the density of the receptor on cell surface (Lesley et al., 2000). Therefore, AH06 may be able to more efficiently bind to and inhibit NCl-N87 cells having a higher density of HER2 than SK-BR-3 cells.

In addition, its anti-cancer activity of AH06 was HER2-specific, and its effect was confirmed at the level of signal transduction, indicating that $\mathrm{AH} 06$ is distinctly superior to hu4D5. Therefore, we suggest that $\mathrm{AH} 06$ could be clinically developed as a therapeutic anti-cancer antibody over hu4D5 (Herceptin).

\section{ACKNOWLEDGMENTS}

We would like to thank Mee Yeon Hwang, Kyung Woo Lee, Ki Young An, Sung Jun Kang, and Dr. Hong Ro Kim for their technical assistance and help, as well as Dr. Sun Young Jeong in the Bio-Medicine laboratory of ChongKunDang Pharmaceutical Corp for proofreading this article. This work was supported by the Development of Antibody drug (Biobetter etc.) based on Platform technology and Antibody engineering (Project No 10031728), a grant funded by the Ministry of Trade, Industry \& Energy Knowledge Economy (MOTIE), Republic of Korea.

\section{REFERENCES}

Back, H., Suk, K.H., Kim, Y.H., and Cha, S.H. (2002). An improved helper phage system for efficient isolation of specific antibody molecules in phage display. Nucleic Acids Res. 30, e18-e26.

Carter, P., Presta, L., Gorman, C.M., Ridgway, J.B., Henner, D., Wong, W.L., Rowland, A.M., Kotts, C., Carver, M.E., and Shepard, H.M. (1992). Humanization of an anti-p185 HER2 antibody for human cancer therapy. Proc. Natl. Acad. Sci. USA 89, 42854289.

Chatellier, J., Van Regenmortel, M.H., Vernet, T., and Altschuh, D. (1996). Functional mapping of conserved residues located at the VL and VH domain interface of a Fab. J. Mol. Biol. 264, 1-6.

Chen, Y., Wiesmann, C., Fuh, G., Li, B., Christinger, H.W., McKay, P., de Vos, A.M., and Lowman, H.B. (1999). Selection and analysis of an optimized anti-VEGF antibody crystal structure of an affinity-matured Fab in complex with antigen. J. Mol. Biol. 293, 865-881.

Genentech, Inc. (2005). Humanized anti-ErbB2 antibodies and treatment with anti-ErbB2 antibodies. US6949245 (US Patent).

Gerstner, R.B., Carter, P., and Lowman, H.B. (2002). Sequence plasticity in the antigen-binding site of a therapeutic anti-HER2 antibody. J. Mol. Biol. 321, 851-862.
Gong, S.J., Jin, C.J., Rha, S.Y., and Chung, H.C. (2004). Growth inhibitory effects of trastuzumab and chemotherapeutic drugs in gastric cancer cell lines. Cancer Lett. 214, 215-224.

Hawkins, R.E., Russell, S.J., Baier, M., and Winter, G. (1993). The contribution of contact and non-contact residues of antibody in the affinity of binding to antigen. The interaction of mutant D1.3 antibodies with lysozyme. J. Mol. Biol. 234, 958-964

Hudziak, R.M., Lewis, G.D., Winget, M., Fendly, B.M., Shepard, H.M., and Ullich, A. (1989). p185 HER2 monoclonal antibody has antiproliferative effects in vitro and sensitizes human breast tumor cells to tumor necrosis factor. Mol. Cell. Biol. 9, 1165-1172.

Johnsson, B., Löfås, S., and Lindquist, G. (1991). Immobilization of proteins to a carboxymethyldextran-modified gold surface for biospecific interaction analysis in surface plasmon resonance sensors. Analyt. Biochem. 198, 268-277.

Kabat, E.A., and Wu, T.T. (1991). Identical $\vee$ region amino acid sequences and segments of sequences in antibodies of different specificities. Relative contributions of $\mathrm{VH}$ and VL gene, minigenes, and complementarity-determining regions to binding of antibody-combining sites. J. Immunol. 147,1709-1719.

Kelley, R.F., and O'Connell, M.P. (1993). Thermodynamic analysis of an antibody functional epitope. Biochemistry 32, 6828-6835.

Kim, J.W., Kim, H.P., Im, S.A., Kang, S., Hur, H.S., Yoon, Y.K., Oh, D.Y., Kim, J.H., Lee, D.S., Kim, T.Y., and Bang, Y.J. (2008). The growth inhibitory effect of lapatinib, a dual inhibitor of EGFR and HER2 tyrosine kinase, in gastric cancer cell lines. Cancer Lett. 272, 296-306.

Lesley, J., Hascall V.C., Tammi, M., and Hyman, R. (2000). Hyaluronan binding by cell surface CD44. J. Biol. Chem. 275, 2696726975.

Lowe, D., Wilkinson T., and Vaughan, T.J., (2012). Affinity maturation approaches for antibody lead optimization. in Antibody Drug Discovery, Wood C.R., (London, UK : Imperial College Press). pp. $85-120$

Macdonald, R.A., Hosking, C.S., and Jones, C.L. (1988). The measurement of relative antibody affinity by ELISA using thiocyanate elution. J. Immunol. Methods. 106,191-194.

Mayumi, O., and Michihiko, K. (2006). Molecular mechanisms of epidermal growth factor receptor (EGFR) activation and response to Gefitinib and other EGFR-targeting drugs. Clin. Cancer Res. 12, 7242-7251.

Nicolas, W., Véronique, D.H., and Martine, J.P. (2008). HER2positive breast cancer: from trastuzumab to innovatory antiHER2 strategies. Clin. Breast Cancer 8, 38-49.

O'Brien, N.A., Browne, B.C., Chow, L., Wang, Y., Ginther, C., Arboledal, J., Duffy, M.J., Crown, J., O'Donovan, N., and Slamon, J.D. (2010). Activated phosphoinositide 3-kinase/AKT signaling confers resistance to Trastuzumab but not Lapatinib. Mol. Cancer Ther. 9, 1489-2211.

Oh, M.Y., oung, Joo, H.Y., Hur, B.U., Jeong, Y.H., and Cha, S.H. (2007). Enhancing phage display of antibody fragments using glll-amber suppression. Gene 386, 81-89.

Phumyen, A., Jumnainsong, A., and Leelayuwat, C. (2012). Improved binding activity of antibodies against major histocompatibility complex Class I chain-related gene A by phage display technology for cancer-targeted therapy. J. Biomed. Biotechnol. 2012,1-8.

Rajpal, A., Beyaz, N., Haber, L., Cappuccilli, G., Yee, H., Bhatt, R.R., Takeuchi, T., Lerner, R.A., and Crea, R. (2005). A general method for greatly improving the affinity of antibodies by using combinatorial libraries. Proc. Natl. Acad. Sci. USA 102, 8466-8471.

Romond, E.H., Perez, E.A., Bryant, J., Suman, V.J., Geyer, C.E. Jr., Davidson, N.E., Tan-Chiu, E., Martino, S., Paik, S., Kaufman, P.A., et al. (2005). Trastuzumab plus adjuvant chemotherapy for operable HER2-positive breast cancer. N. Engl. J. Med. 353 1673-1684.

Schier, R., McCall, A., Adams, G.P., Marshall, K.W., Merritt, H., Yim, M., Crawford, R.S., Weiner, L.M., Marks, C., and Marks, J.D. (1996). Isolation of picomolar affinity anti-c-erbB-2 single-chain Fv by molecular evolution of the complementarity determining regions in the center of the antibody binding site. J. Mol. Biol. 263, 551-567.

Shepard, H.M., Lewis, G.D., Sarup, J.C., Fendly, B.M., Maneval, D., Mordenti, J., Figari, I., Kotts, C.E., Palladino, M.A. Jr, Ullrich, A., et al. (1991). Monoclonal antibody therapy of human cancer: taking the HER2 protooncogene to the clinic. J. Clin. Immunol. 


\section{$11,117-127$.}

Sidhu, S.S, Lowman, H.B., Cunningham, B.C., and Wells, J.A. (2000). Phage display for selection of novel binding peptides. Methods Enzymol. 328, 333-363.

Sliwkowski, M.X., Lofgren, J.A., Lewis, G.D., Hotaling, T.E., Fendly, B.M., and Fox, J.A. (1999). Nonclinical studies addressing the mechanism of action of trastuzumab (Herceptin). Semin. Oncol. $26,60-70$.

Song, S.Y., Hur, B.U., Lee, K.W., Choi, H.J., Kim, S.S., Kang, K., and Cha, S.H. (2009). Successful application of the dual-vector system II in creating a reliable phage-displayed combinatorial Fab library. Mol. Cells 27, 313-319.

Wang, Z., Wang, Y., Li, Z., Li, J., and Dong, Z. (2000). Humaniza- tion of a mouse monoclonal antibody neutralizing TNF-alpha by guided selection. J. Immunol. Methods 241, 171-184.

Yakes, F.M., Chinratanalab, W., Ritter, C.A., King, W., Seelig, S., and Arteaga, C.L. (2002). Herceptin-induced inhibition of phosphatidylinositol-3 kinase and Akt is required for antibodymediated effects on p27, cyclin D1, and antitumor action. Cancer Res. 62, 4132-4141.

Yoon, S.O., Lee, T.S., Kim, S.J., Jang, M.H., Kang. Y.J., Park, J.H., Kim, K.S., Lee, H.S., Ryu, C.J., Gonzales, N.R., et al. (2006). Construction, affinity maturation, and biological characterization of an anti-tumor-associated glycoprotein-72 humanized antibody. J. Biol. Chem. 281, 6985-6992. 